\title{
Characterizing Ice-Scattering Homogeneity in TRMM Microwave Imagers and Its Influence on Oceanic Rain-Rate Estimation Bias of TRMM Precipitation Radar
}

\author{
Andung Bayu Sekaranom ${ }^{1,2, *}$, Emilya Nurjani ${ }^{1}$, Sandy Budi Wibowo ${ }^{3}$ (i) and Hirohiko Masunaga ${ }^{4}$ \\ 1 Department of Environmental Geography, Faculty of Geography, Universitas Gadjah Mada, \\ Yogyakarta 55281, Indonesia; emilya.nurjani@ugm.ac.id \\ 2 Center for Disaster Studies, Universitas Gadjah Mada, Yogyakarta 55281, Indonesia \\ 3 Department of Geographic Information Science, Faculty of Geography, Universitas Gadjah Mada, \\ Yogyakarta 55281, Indonesia; sandy_budi_wibowo@ugm.ac.id \\ 4 Institute for Space-Earth Environmental Research, Nagoya University, Furo-cho Chikusa-ku, \\ Nagoya 464-8601, Japan; masunaga@nagoya-u.jp \\ * Correspondence: andungbayu@geo.ugm.ac.id
}

\section{check for} updates

Citation: Sekaranom, A.B.; Nurjani, E.; Wibowo, S.B.; Masunaga, H. Characterizing Ice-Scattering Homogeneity in TRMM Microwave Imagers and Its Influence on Oceanic Rain-Rate Estimation Bias of TRMM Precipitation Radar. Atmosphere 2021, 12, 1377. https://doi.org/10.3390/ atmos12111377

Academic Editor:

Sergio Fernández-González

Received: 12 September 2021

Accepted: 18 October 2021

Published: 21 October 2021

Publisher's Note: MDPI stays neutral with regard to jurisdictional claims in published maps and institutional affiliations.

Copyright: (c) 2021 by the authors. Licensee MDPI, Basel, Switzerland. This article is an open access article distributed under the terms and conditions of the Creative Commons Attribution (CC BY) license (https:// creativecommons.org/licenses/by/ $4.0 /)$.

\begin{abstract}
Precipitation homogeneity is one of the main factors that contribute to the difference in the rain-rate estimation from meteorological satellites. Using the Tropical Rainfall Measuring Mission (TRMM) products, this paper aims to characterize the homogeneity of ice-scattering signals from TRMM Microwave Imagers (TMIs) as related to rain-rate estimation bias with TRMM Precipitation Radar (PR). Statistical information about the polarization-corrected brightness temperature (PCT) from the TMI $85 \mathrm{GHz}$ band is obtained over the global ocean in the tropics. The characteristics are the fraction of PCT below a given threshold, the minimum value, and the standard deviation that are calculated at a $0.25^{\circ} \times 0.25^{\circ}$ grid level. The average values of rain-rate estimation from TRMM PR and TMI in the same grid position and time are then compared. This result indicates that the rain-rate estimation bias is influenced by the homogeneity and organization of precipitation systems. Using the statistical signature of ice-scattering signals at the grid level, an adjustment was implemented for TMI rain-rate estimation. The results could produce rain-rate estimations that conform more to PR, particularly for the inhomogeneous precipitation system mostly affected by stratiform rain. The characterization of ice-scattering signals as a proxy to the precipitation homogeneity, as presented in this research, could be implemented in order to improve the accuracy of satellite rain-rate estimation in the future.
\end{abstract}

Keywords: rain-rate estimation; precipitation homogeneity; Tropical Rainfall Measuring Mission

\section{Introduction}

Rainfall analysis based on satellite precipitation estimation has yielded important information on tropical precipitation systems that are less observable from the ground. One of the estimation products that makes a significant contribution is the observation of the Tropical Rainfall Measuring Mission (TRMM). TRMM, launched in 1997, is the first satellite that mounts a spaceborne precipitation radar (PR) aimed at identifying raindropsize particles [1]. The results of the TRMM observations have resulted in a more detailed understanding of precipitation in the tropics. One example is the TRMM PR observation, which can capture data related to the three-dimensional profile of tropical cyclones and how they evolve. The three-dimensional profiling ability also has a significant contribution to the characterization of diurnal rainfall patterns over tropical regions [2-4]. The information gathered by TRMM also provides a significant contribution to numerical weather prediction and climate models, particularly in terms of evaluating the physical parameters of clouds and precipitation $[5,6]$. 
In addition to precipitation radar (PR), TRMM also contains a number of comprehensive sensors, including the TRMM microwave imager (TMI) [7]. Rain-rate estimation from TRMM PR and TMI, together with other sensors and satellites, produces a combined product called TRMM Multisatellite Precipitation Analysis (TMPA) [8]. The two rain-rate estimation products mentioned above play an important role in producing rainfall estimates for the TMPA and other derivative products. One of the most important points to mention is that PR observations are spatially and temporally coincident with TMIs, which could produce a calibration reference between active-passive sensors $[9,10]$. The calibration reference is useful, not only for TRMM, but also for next-generation satellites.

The PR sensor on the TRMM operates at a radar frequency of $13.8 \mathrm{GHz}$, where the rainfall information $(R)$ is derived from the radar reflectivity $(Z)$ received by the sensor [11]. The rainfall estimation on $P R$ is based on the empirical relationship $Z=a R^{b}$, which shows the relationship between radar reflectivity and rain-rate by considering defined constants, $a$ and $b$. This relationship is related to the drop size distribution (DSD), where in the Rayleigh limit, the radar reflectivity is the sixth moment of the DSD. The assumptions used in determining the DSD are often one of the causes of differences between the estimated results and surface observations [12,13]. PR can also experience significant attenuation in heavy rainfall events, and therefore attenuation needs to be corrected. Correction of attenuation in PR is carried out using a combination of two approaches. The first approach is the Hitschfeld-Bordan method, which is not reliable for heavy rainfall but produces better estimates at low rain-rates. The second approach is surface reference technique (SRT) methods, which have opposite characteristics to the Hitschfeld-Bordan method [14]. The use of a hybrid approach covers the weaknesses of each method. However, the assumption of attenuation correction of PR is often thought to be one of the sources of differences between rainfall estimates and surface observations [15].

Precipitation estimation in TMI is based on the relationship between the brightness temperature of several bands and precipitation. The 10,19, 21, and $37 \mathrm{GHz}$ bands capture microwave emissions from precipitating particles, while the $85 \mathrm{GHz}$ band captures icescattering signals reflected by cloud tops [16]. The TMI algorithm uses a Bayesian approach to determine the most likely amount of precipitation based on signatures from a set of signals captured by those bands, using the hydrometeor profile database as a reference. One of the disadvantages of TMI is the low spatial resolution of emission bands. Thus, the TMI may not be very sensitive to small-scale precipitation systems $[17,18]$. Another weakness of TMI is that the variation in emission from the land surface results in interference with the signal that is received by the emission bands [19]. Therefore, up to the current version (version 7), the rainfall estimation algorithm on land is based on ice-scattering bands. In the ocean, emission and ice-scattering signals can be well received by sensors and can become the basis for the estimation of precipitation in the ocean [1].

This paper focuses on the estimation products of PR and TMI in the tropical ocean region to show how the different principles of active and passive sensors can affect the estimation results. One of the important points to be noted from previous studies is that the differences in the estimation generated from these two sensors are regionally dependent [20]. For example, PR tends to identify higher precipitation than does TMI in the northern Indian Ocean. In contrast, TMI results in a higher estimate of precipitation than PR in the eastern Pacific Ocean. Furthermore, previous research shows that the TMI tends to produce higher estimates of precipitation in organized but shallow precipitation systems [21]. The above example indicates that precipitation-related processes that compose the climatological characteristics of each region could affect the estimation [18].

The second important point to note in the rain-rate estimation difference of the two products is the aspect of microphysical dependence [22,23]. For example, a comparison of supercells over Oklahoma and shallow rain over Yemen shows that the precipitation system contains a large ice-water content that is typical during a supercell, and the TMI detects a larger rain area and estimates a higher rain-rate than PR [10]. However, when the low ice-water content is low, particularly in a shallow precipitation system, the PR detects 
a larger rain area and estimates a higher rain-rate than the TMI [21]. The TMI rain-rate estimation is also known to have a strong relationship with the ice-water content [24]. Ice-scattering signals detected by the $85 \mathrm{GHz}$ channel in the TMI peaked when the cloud height was at a maximum. The maximum rainfall is often estimated in the TMI algorithm under the above conditions [25]. However, there are a number of events where PR detects maximum rainfall where ice particles are lower than those identified by the TMI [13]. The above conditions could presumably occur when intense collision and coalescence processes occur [6,26].

The third important point is that the PR and TMI rain estimation difference is related to the spatial homogeneity of the precipitation. PR has a higher spatial resolution (approximately $4 \mathrm{~km}$ preboost and up to $5 \mathrm{~km}$ postboost) than TMI [27]. The TMI has varied resolution depending on its bands. The highest resolution is from the $85 \mathrm{GHz}$ band ( $5 \mathrm{~km} \times 7 \mathrm{~km}$ in preboost $/ 6 \mathrm{~km} \times 8 \mathrm{~km}$ in postboost), while the lowest is from the $10 \mathrm{GHz}$ band (approximately $60 \mathrm{~km}$ in width during preboost and up to $70 \mathrm{~km}$ during postboost). As mentioned earlier, one of the weaknesses of TMI is in detecting small-scale precipitation systems [21]. For example, TMI shows the contribution of shallow organized precipitation but shows a lower contribution than the PR for deep precipitation systems [21]. When the two products are compared statistically at the grid scale level, the PR shows higher rain-rate variation than the TMI [13]. This means that the TMI is less sensitive to high precipitation variability at the grid scale.

The above discussion highlights how the PR and TMI estimations could be biased, because each region has different precipitation characteristics. The main objective of this research is to find whether spatial homogeneity information could be useful in explaining the precipitation estimation difference between the two products. In this research, we use the ice-scattering signatures obtained by the TMI $85 \mathrm{GHz}$ channel as a proxy for the scale of homogeneity. The TMI $85 \mathrm{GHz}$ channels are used as a proxy for ice particles near the upper part of clouds that can vary on different scales of precipitation. The following section explains the detailed TRMM products and the processing methods used in this research. The results section is intended to explain how understanding the homogeneity and properties of the ice-scattering signature could be related to the rain-rate estimation difference between the PR and TMI. The discussion section explains this in a more general way and the manner in which the above information could be useful in future algorithm development is summarized in the last section.

\section{Materials and Methods}

The focus of this section is to explain the type of TRMM data used to characterize the PR and TMI rain-rate estimation differences, particularly using ice-scattering characteristics at the grid level. The TRMM version 7 data after postboost were used for the analysis, starting from 1 January 2002 to 31 December 2006 (orbit number 23,559 to 52,014). We intended to evaluate precipitation estimation differences over the ocean, where all TMI channels were used as the basis of the estimation inside the TMI algorithm over the ocean. The focus is the tropical ocean, between $15^{\circ}$ north and $15^{\circ}$ south over the global tropics. The main product to be compared is the level 2 products, particularly near surface rain-rate estimation from PR2A25 and surface rain-rate estimation from TMI 2A12. The TMI 85 $\mathrm{GHz}$ ice-scattering signals were obtained from TMI 1B11. In addition to the above products, convective/stratiform information was obtained from PR2A23. We limit the data to grids where the average rain-rates are higher than $1 \mathrm{~mm} / \mathrm{h}$ from PR2A25 and TMI2A12. This threshold was selected because it is higher than the minimum detection from PR and TMI [1]. Therefore, we avoid false signals of rain/no-rain conditions that are often found at lower rain-rates [28].

The comparison of the data is conducted at the grid level to populate a set of data inside the grid where PR and TMI observe the same location at almost the same time. We use a $0.25^{\circ} \times 0.25^{\circ}$ grid where the precipitation estimation and other related data at the original resolution were stored. The $0.25^{\circ} \times 0.25^{\circ}$ spatial resolution is selected because it contains a considerable amount of original pixel data from PR and TMI. The above spatial 
resolution is also the same as the TMPA product, so the adjustment presented in this paper can be useful for operational purposes. In this research, the average rain-rates from PR and TMI inside the $0.25^{\circ}$ grid are calculated, and the difference is represented in terms of the gridded rain-rate from PR minus the gridded rain-rate from TMI. The convective/stratiform classification of each grid is determined by the most dominant type, as populated from PR2A23. The TMI ice-scattering channel $(85 \mathrm{GHz})$ brightness temperature data from $1 \mathrm{~B} 11$ are also populated at the same grid. The vertical and horizontal polarizations $\left(T_{B V}\right.$ and $T_{B H}$, respectively) from the TMI $85 \mathrm{GHz}$ channel are utilized to calculate the polarizationcorrected brightness temperature (PCT) [29], where:

$$
\mathrm{PCT}=1.818 \mathrm{~T}_{B V}-0.818 \mathrm{~T}_{B H}
$$

In short, each grid contains the average rain-rate for PR and TMI, statistical information about TMI $85 \mathrm{GHz}$ PCT, and convective/stratiform precipitation.

The gridded TMI $85 \mathrm{GHz}$ PCT data are the focus in explaining the difference between rain-rate estimations of the two products. Figure 1 shows a comparison between the two precipitation systems inside the $0.25^{\circ}$ grid (red color bounding box). The images in the top indicate a shallow precipitation system where the TMI $85 \mathrm{GHz}$ PCT is warmer than the bottom images (later classified as a deep precipitation system). The first image in the top left shows the PR rain-rate estimation value in its original footprint, while the second in the middle is for TMI rain-rate estimation. Note that the average rain-rates inside the grid are $5.9 \mathrm{~mm} / \mathrm{h}$ and $3.7 \mathrm{~mm} / \mathrm{h}$ for PR and TMI, respectively. The difference between the gridded rain-rate from the two products is not as high as that in the bottom images. The first image in the bottom left shows the PR rain-rate estimation value, where the grid average is $16.2 \mathrm{~mm} / \mathrm{h}$. The TMI gridded rain-rate estimation value is only $5.7 \mathrm{~mm} / \mathrm{h}$. The interesting point is TMI $85 \mathrm{GHz}$ data in the right part of the figure. The standard deviation for TMI $85 \mathrm{GHz}$ PCT inside the grid is lower for the top images than for the bottom images. The TMI $85 \mathrm{GHz}$ standard deviation may reflect the variation in precipitation in each $0.25^{\circ}$ grid. For example, a low standard deviation might be associated with a homogeneous precipitation system, while high variation in a grid is likely to be associated with a specialization system that is less homogeneous.

In addition to the standard deviation, the difference in shallow/deep precipitation systems could be an important source to address. Therefore, we calculate the minimum TMI $85 \mathrm{GHz}$ PCT (denoted as min $_{T M I} P C T$ ) inside each grid. A brightness temperature threshold of $240 \mathrm{~K}$ is used to classify shallow or deep precipitation systems [30]. When the minimum TMI $85 \mathrm{GHz}$ PCT inside a grid is less than $240 \mathrm{~K}$, it is classified as a deep precipitation system, and vice versa for a shallow precipitation system. To further analyze the homogeneity inside the $0.25^{\circ}$ grid, we use the fraction of TMI $85 \mathrm{GHz}$ PCT pixels that are lower than $240 \mathrm{~K}$ for deep precipitation grids. For shallow precipitation grids (characterized by warmer PCT than the deep precipitation system), we use the fraction of TMI 85 GHz PCT pixels containing brightness temperatures of less than $273 \mathrm{~K}$.

Information about homogeneity is not considered by the original TMI ocean algorithm, since the estimations are estimated based on each pixel. However, it could be considered in a larger scope/area (using $0.25^{\circ} \times 0.25^{\circ}$ spatial resolution in this research). The question is to what degree can it influence the rain-rate estimation bias between PR and TMI. As suggested in the above paragraph, the grid-scale homogeneity is characterized by standard deviations of ice-scattering signals inside the $0.25^{\circ}$ grid $\left(\sigma_{T M I} P C T\right)$ and fractions of ice-scattering signals $\left(f_{T M I_{-} P C T}\right)$ lower than the threshold $(240 \mathrm{~K}$ and $273 \mathrm{~K}$ for deep and shallow precipitation, respectively). To measure the degree to which both parameters can influence the rain-rate estimation, an adjustment was conducted to derive the most likely gridded rain-rate estimated by $\mathrm{PR}\left(R_{P R}\right)$ using a set of data derived from TMI as the correction factor $\left(T_{B 85} C F\right)$. $T_{B 85} C F$ consists of four parameters, namely, the estimated gridded rain-rate from TMI $\left(R_{T M I}\right)$, minimum gridded TMI $85 \mathrm{GHz}$ PCT $\left(\min _{T M I_{-} P C T}\right)$, $\sigma_{T M I} P C T$, and $f_{T M I \_P C T}$. 
PR2A25 Rain-rate [mm/h]

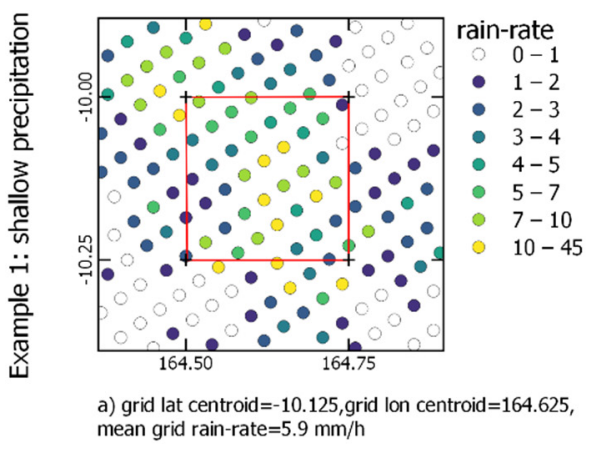
mean grid rain-rate $=5.9 \mathrm{~mm} / \mathrm{h}$

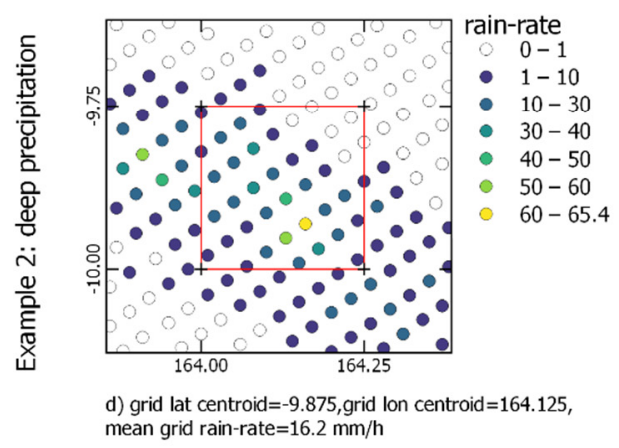

TMI2A12 Rain-rate [mm/h]

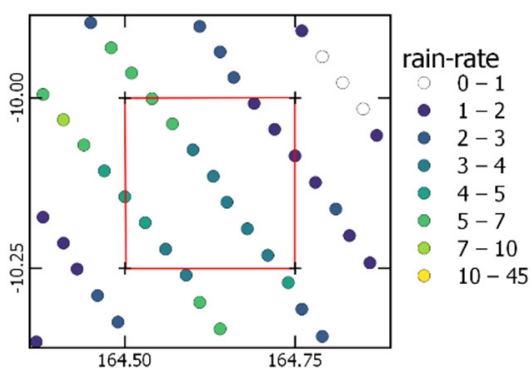

b) grid lat centroid $=-10.125$, grid lon centroid $=164.625$, mean grid rain-rate $=3.7 \mathrm{~mm} / \mathrm{h}$

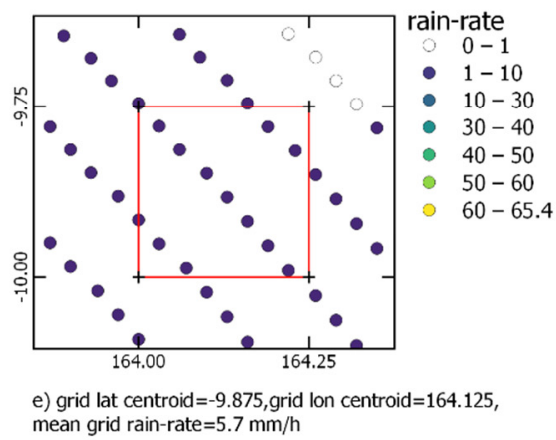

TMI1B11 PCT [K]

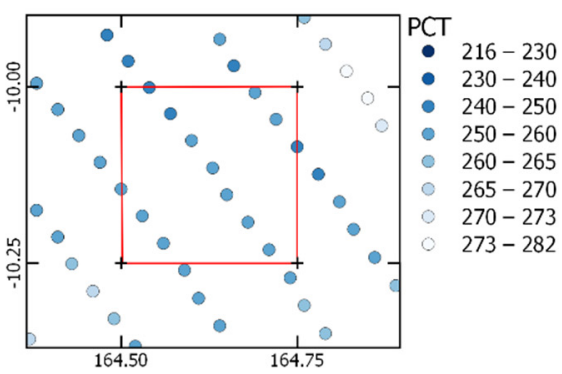

c) grid lat centroid $=-10.125$, grid lon centroid $=164.625$, min PCT $=247.3$, stdev $P C T=11.48$

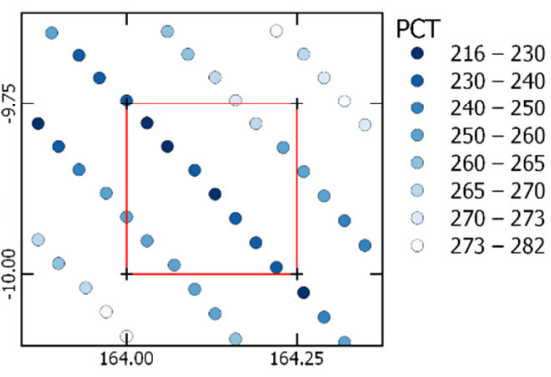

f) grid lat centroid $=-9.875$, grid lon centroid $=164.125$, $\min P C T=218.7$, stdev $P C T=15.79$

Figure 1. Example of (a) PR rain-rate estimation, (b) TMI rain-rate estimation, and (c) TMI 85 GHz PCT for a precipitation event captured by TRMM at the same coordinate and time. The red bounding box shows a $0.25^{\circ} \times 0.25^{\circ}$ grid as the basis of comparison. Note that the 1st example $(\mathbf{a}-\mathbf{c})$ at the top has a warmer PCT (indicating a shallow precipitation system) than the 2nd example (d-f) at the bottom (indicating a deep precipitation system).

It should be noted that there was no ground validation in this research, so the gridded PR data were considered the true value only to compare the degree to which they could match the TMI. A rain information database was developed using the five years of observation previously mentioned. First, the database is separated for shallow (minimum gridded TMI85GHZ PCT > $240 \mathrm{~K}$ ) and deep precipitation systems (minimum gridded TMI85GHZ $\mathrm{PCT}<240 \mathrm{~K}$ ). Each rain event in the grid level and its corresponding correction factor were then listed in the database. Therefore each set of data contains $R_{P R}$ and its corresponding $T_{B 85} C F$. Convective/stratiform fractions were also calculated for each set of data to further explain the result. The PR and TMI rain-rates contained in the database were then binned for each $0.5 \mathrm{~mm}$. The $\min _{T M I_{-} P C T}, \sigma_{T M I_{-} P C T}$, and $f_{T M I_{-} P C T}$ were also binned for each $2 \mathrm{~K}$, $1.0 \mathrm{~mm}$, and 0.1 respectively. For each unique set of the binned correction factor $\left(T_{B 85} C F\right)$, the probability $(P)$ of PR gridded rain-rate was evaluated (Figure 2). The adjusted rain-rate $\left(R_{a d j}\right)$ was calculated based on the sum of each possible rain-rate in the database that weighted (multiplied) by its corresponding probability, where:

$$
R_{a d j}=\sum R_{P R} \cdot P\left(R_{P R} \mid T_{B 85} C F\right)
$$

The above adjustment was calculated based on a five-year period (2002 to 2006) and needs to be validated using observation data outside that range. In this paper, the validation period is taken by contrasting El Niño and La Niña events, because the two periods are known to have different characteristics in terms of precipitation organization [31]. It is also important to identify whether the algorithm performed well only in a specific time period (during El Niño/La Niña). The El Niño validation period was conducted from 1 December 2007, to 28 February 2008, while the La Niña validation period was from 1 December 2009, to 28 February 2010. For any rain event in both periods, the $T_{B 85} C F$ was obtained and matched with the database. The adjusted rain rate was calculated based on a set of rain-rate probabilities that correspond to any given $T_{B 85} C F$ as shown in 
Equation (2). The adjusted rain-rate was then compared with the original TMI rain-rate (before adjustment) and PR rain-rate at the same grid. The differences were explained using joint histogram, correlation (r), and Root Mean Square Error (RMSE).

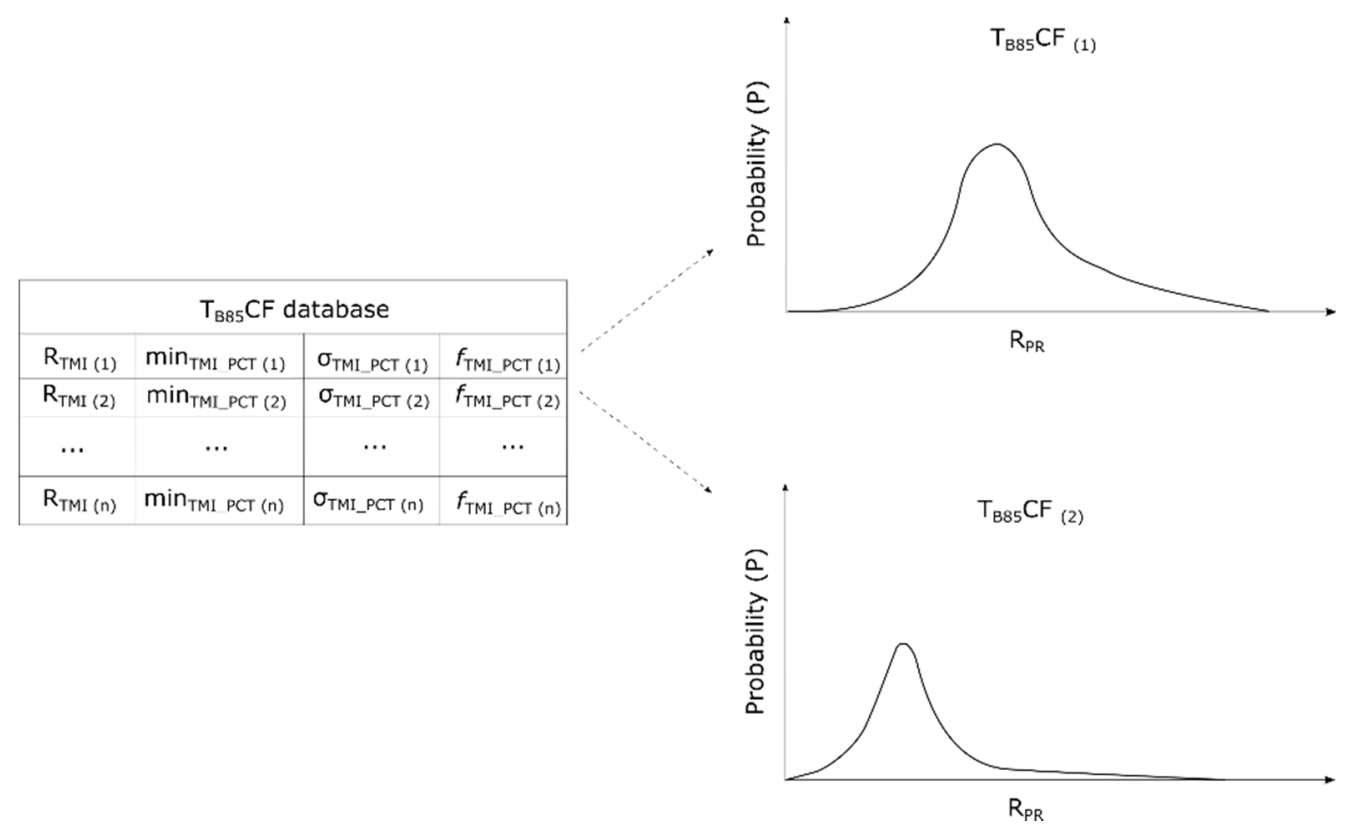

Figure 2. Illustration of the database that contain unique binned values of correction factor parameters $\left(T_{B 85} C F\right)$ and the corresponding probability of PR gridded rain-rate.

\section{Results}

3.1. General Characteristics of the Ice-Scattering Homogeneity and Its Influence on PR-TMI Rain-Rate Estimation Bias

The first part of this section is intended to explain the PR-TMI rain-rate estimation difference by using examples from El Niño events in 2007 and La Niña events in 2009 for comparison. The comparison also considers a condition where the PR estimation is higher than TMI and vice versa. The general explanation presented in this subsection is intended to introduce the difference inside the database, which is further explained in the next section.

As mentioned in the previous section, the rain-rate estimation difference between the two products is apparent between El Niño and La Niña [30]. The TMI rain-rate estimation is often higher during El Niño than that of PR. Previous research results also indicate that the overestimation comes from organized precipitation over the East Pacific Ocean, particularly during El Niño [21]. The organized precipitation appears to be shallow, and the PR therefore estimates a lower rain-rate than TMI. To explain the difference, PR and TMI rain-rate contributions between the two events are compared. The fraction of specific PCT values below a given threshold $\left(f_{T M I} P C T\right)$ is used to represent the difference. The $273 \mathrm{~K}$ threshold $\left(f_{T M I_{-} P C T_{273}}\right)$ is used for shallow precipitation systems, while the $240 \mathrm{~K}$ threshold $\left(f_{T M I} P C T_{240}\right)$ threshold is used for deep precipitation systems.

Figure 3 shows the comparison of rain-rate contributions for shallow precipitation systems between PR and TMI gridded precipitation during El Niño in 2007 and La Niña in 2009. The fraction $\left(f_{T M I_{-} P C T_{273}}\right)$ is classified into three classes based on its possible minimum to maximum range. A low fraction (less than or equal to 0.33 ) might be associated with less organized precipitation, while a higher fraction indicates more organized precipitation (classified as medium if falls between $0.33-0.67$ and higher if more than 0.67 ). The results show that the PR rain-rate contribution is lower than the TMI when the PCT fraction is higher, particularly for shallow precipitation. The difference is higher during 
El Niño since the rain-rate contribution is the lowest for PR. In contrast, the TMI rain-rate contributions are higher, since the value is almost equal for different classes of fractions.
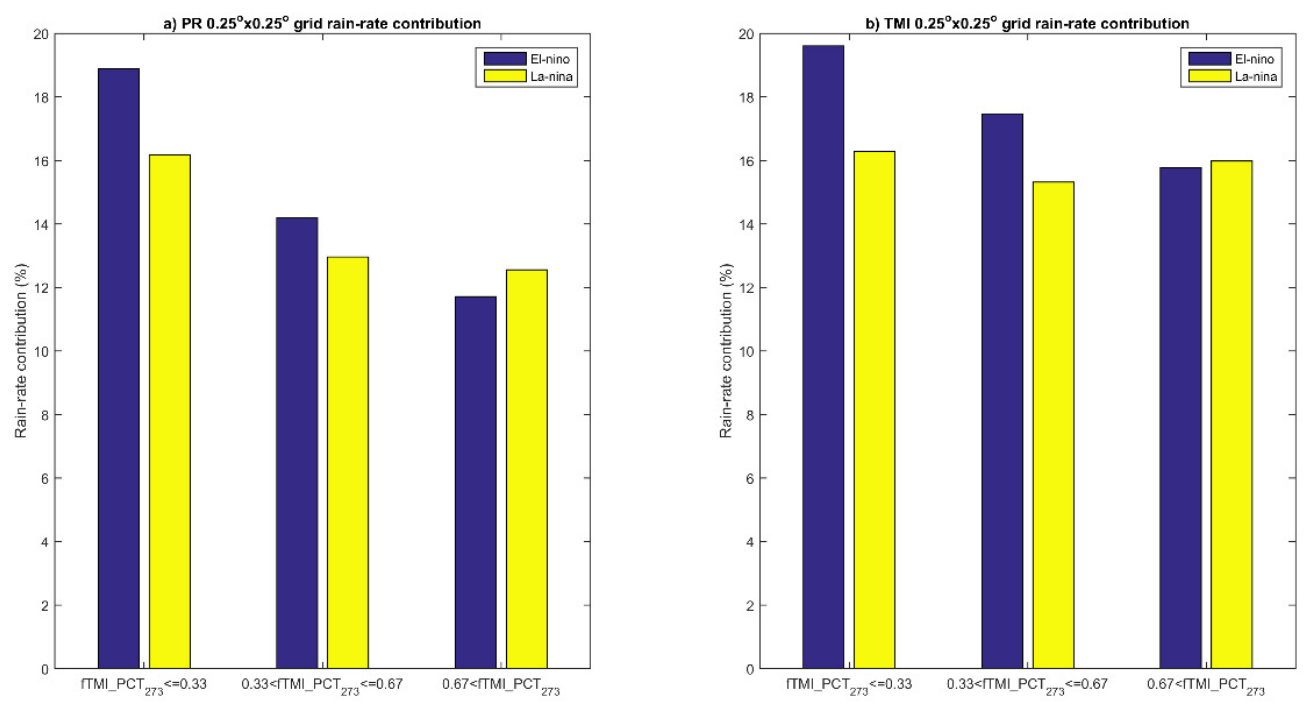

Figure 3. Comparison of PR rain-rate contribution (a) and TMI rain-rate contribution (b) for shallow precipitation systems during El Niño events in 2007 and La Niña events in 2009 over the global tropical ocean. (Source: data processing).

Figure 4 shows the comparison of rain-rate contributions between PR and TMI in terms of deep precipitation systems. Both products indicate a higher rain-rate contribution of the deep precipitation system during La Niña compared to El Niño. The two products also conform to the higher contribution of precipitation from the shallow precipitation system during El Niño. However, it is clear that the PR shows a higher contribution of the deep precipitation that contains a low PCT fraction compared to the TMI. The PR also estimates a higher contribution from precipitation with a medium PCT fraction than from precipitation with a high PCT fraction. The rain contribution difference between the medium and high PCT fractions from the TMI is less significant than that from the PR.
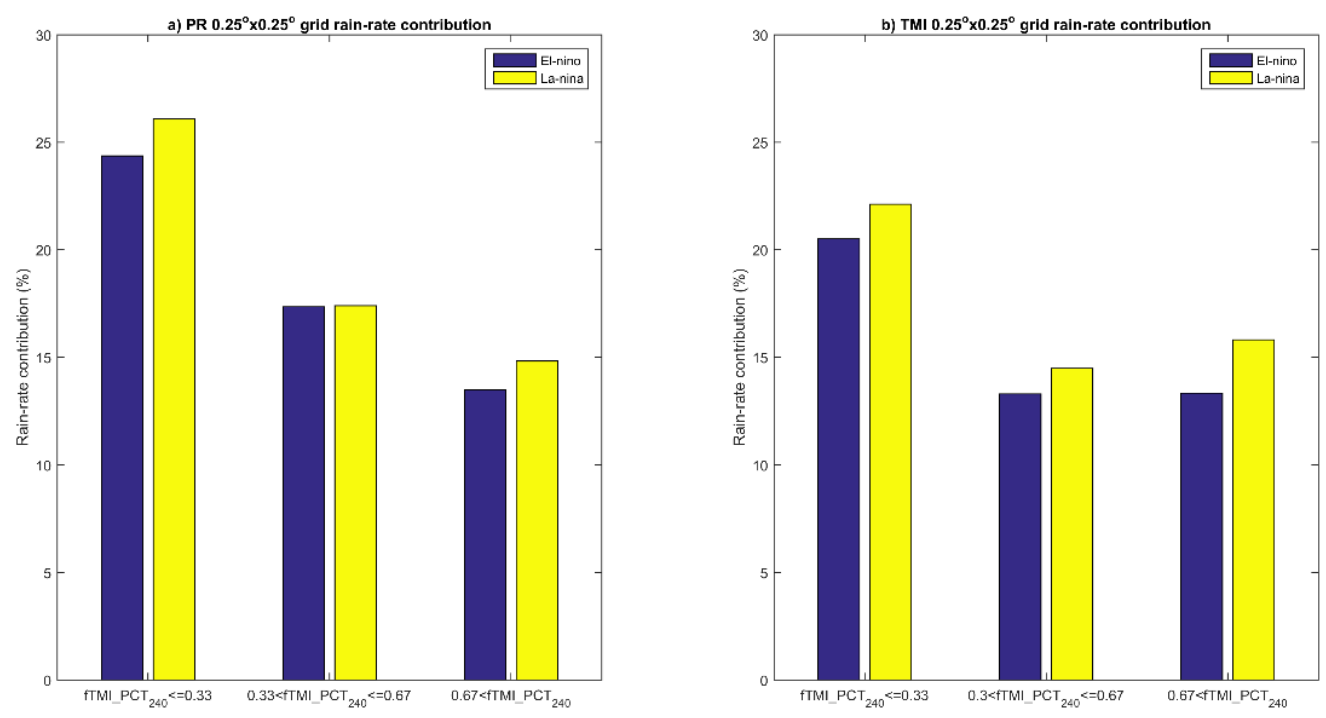

Figure 4. Comparison of PR rain-rate contribution (a) and TMI rain-rate contribution (b) for deep precipitation systems during El Niño events in 2007 and La Niña events in 2009 over the global tropical ocean. (Source: data processing).

Table 1 shows a significant difference when considering the fraction of the PCT threshold for shallow precipitation systems in general, not only in relation to the comparison between El Niño and La Niña which is explained above. The difference is separated by whether the PR rain-rate estimation is higher than the TMI $\left(\mathrm{PR}_{R R}>\mathrm{TMI}_{R R}\right)$ and vice 
versa $\left(\mathrm{PR}_{\mathrm{RR}}<\mathrm{TMI}_{\mathrm{RR}}\right)$. The difference is characterized by the average value of the standard deviation $\left(\sigma_{T M I_{-} P C T}\right)$, convective fraction $\left(f_{P R_{-} c o n v}\right)$, and the minimum PCT value $\left(\operatorname{Min}_{T M I_{-} P C T}\right)$. The convective fraction obtained from the ratio of convective pixels to the sum of convective and stratiform pixels from TRMM PR2A23. The result shows that a higher estimation achieved by PR (compared to TMI) is associated with a large variation in PCT captured by the TMI $85 \mathrm{GHz}$ channel (higher standard deviation). The TMI could also estimate a higher rain-rate than PR but was associated with a lower variation in PCT than when PR estimated a higher rain-rate than TMI. A comparison of the $f_{P R \_c o n v}$ from the PR rain type product at the same grid position indicates that the convective fraction is lower for a condition where PR identifies a higher rain-rate than TMI, compared to when the TMI estimates a higher rain-rate than PR. There is also a difference in Min ${ }_{T M I} P C T$ when PR estimates a higher rain-rate than TMI and vice versa. The higher rain-rate estimation from PR is also associated with a lower value of $M_{T n_{T M I} P C T}$, compared to when TMI estimates a higher rain-rate. The above differences are found from precipitation with low to high PCT fractions. The above properties are similar for deep precipitation systems (Table 2), although the difference is higher in terms of $\sigma_{T M I_{-} P C T}$ and $M i n_{T M I_{-} P C T}$.

Table 1. Difference in the statistical characteristics of gridded TMI $85 \mathrm{GHz}$ PCT standard deviation, PR convective fraction, and minimum TMI $85 \mathrm{GHz}$ PCT for shallow precipitation system based on fraction of number of TMI 85 GHz PCT below $273 \mathrm{~K}$ threshold (Source: data processing).

\begin{tabular}{|c|c|c|c|c|c|c|}
\hline \multirow{2}{*}{$\begin{array}{c}0.25^{\circ} \times 0.25^{\circ} \\
\text { Grid }\end{array}$} & \multicolumn{2}{|c|}{$f_{T M I \_P C T_{273}} \leq 0.33$} & \multicolumn{2}{|c|}{$0.33<f_{T M I \_P C T_{273}} \leq 0.67$} & \multicolumn{2}{|c|}{$0.67<f_{T M I \_P C T_{273}}$} \\
\hline & $P_{R R}>T_{M I_{R R}}$ & $\mathrm{PR}_{\mathrm{RR}}<\mathrm{TMI}_{\mathrm{RR}}$ & $\mathrm{PR}_{\mathrm{RR}}>\mathrm{TMI}_{\mathrm{RR}}$ & $\mathrm{PR}_{\mathrm{RR}}<\mathrm{TMI}_{\mathrm{RR}}$ & $\mathrm{PR}_{\mathrm{RR}}>\mathrm{TMI}_{\mathrm{RR}}$ & $\mathrm{PR}_{\mathrm{RR}}<\mathrm{TMI}_{\mathrm{RR}}$ \\
\hline$\sigma_{T M I \_P C T}$ & 5.63 & 4.44 & 6.98 & 5.87 & 6.26 & 5.85 \\
\hline$f_{P R \_c o n v}$ & 0.47 & 0.77 & 0.64 & 0.87 & 0.90 & 0.96 \\
\hline Min $_{T M I}$ PCT & 259.35 & 262.37 & 253.37 & 256.35 & 249.36 & 250.48 \\
\hline
\end{tabular}

Table 2. Difference in the statistical characteristics of gridded TMI $85 \mathrm{GHz}$ PCT standard deviation, PR convective fraction, and minimum TMI $85 \mathrm{GHz}$ PCT for deep precipitation system based on fraction of number of TMI 85 GHz PCT below 273 K threshold (Source: data processing).

\begin{tabular}{|c|c|c|c|c|c|c|}
\hline \multirow{2}{*}{$\begin{array}{c}0.25^{\circ} \times 0.25^{\circ} \\
\text { Grid }\end{array}$} & \multicolumn{2}{|c|}{$f_{\text {TMI_PC } T_{240}} \leq 0.33$} & \multicolumn{2}{|c|}{$0.33<f_{T_{M I}{ }_{-} P C T_{240}} \leq 0.67$} & \multicolumn{2}{|c|}{$0.67<f_{T M I \_P C T_{240}}$} \\
\hline & $\mathrm{PR}_{\mathrm{RR}}>\mathrm{TMI}_{\mathrm{RR}}$ & $\mathrm{PR}_{\mathrm{RR}}<\mathrm{TMI}_{\mathrm{RR}}$ & $\mathrm{PR}_{\mathrm{RR}}>\mathrm{TMI}_{\mathrm{RR}}$ & $\mathrm{PR}_{\mathrm{RR}}<\mathrm{TMI}_{\mathrm{RR}}$ & $\mathrm{PR}_{\mathrm{RR}}>\mathrm{TMI}_{\mathrm{RR}}$ & $\mathrm{PR}_{\mathrm{RR}}<\mathrm{TMI}_{\mathrm{RR}}$ \\
\hline$\sigma_{T M I \_P C T}$ & 10.86 & 7.47 & 15.02 & 9.19 & 15.98 & 9.81 \\
\hline$f_{P R_{-} \text {conv }}$ & 0.62 & 0.87 & 0.68 & 0.90 & 0.71 & 0.90 \\
\hline Min $_{T M I \_P C T}$ & 212.97 & 221.80 & 197.89 & 214.12 & 186.68 & 204.46 \\
\hline
\end{tabular}

3.2. The PR-TMI Rain-Rate Estimation Difference as Related to the TMI 85 GHz PCT Minimum Value and Standard Deviation

This subsection focuses on two significant points to be noted in the rain-rate database, namely, the minimum value TMI $85 \mathrm{GHz}$ PCT inside each grid and its deviation. As suggested in the previous section, there are differences in the rain-rate estimation between the two products, which are influenced by precipitation inhomogeneity. The difference in the minimum TMI $85 \mathrm{GHz}$ PCT value $\left(M_{\text {in }}\right.$ TMI_PCT $\left._{-}\right)$and its standard deviation $\left(\sigma_{T M I \_P C T}\right)$ are explained in this section using information obtained from the database. The first result in Figure 5 shows the joint frequency histogram of the rain-rate difference in terms of grid scale, regarding. Min ${ }_{T M I}{ }_{-} P C T$. In this subsection, the differences are separated between convective and stratiform precipitation based on dominant rain type pixels inside the grid. The result shows that the difference in convective precipitation is not symmetrical between the negative and positive values. For convective rain grids, the frequency is higher for the negative value (PR estimate less rain-rate than TMI) for PCT ranges from approximately $220 \mathrm{~K}$ to $260 \mathrm{~K}$. The positive bias is higher in lower PCT (PR estimate higher rain-rate than $\mathrm{TMI}$ ) ranges from $100 \mathrm{~K}$ to $220 \mathrm{~K}$. For the stratiform cases, it is clear that the positive bias is more dominant from the lowest PCT range at $100 \mathrm{~K}$ to $270 \mathrm{~K}$. 

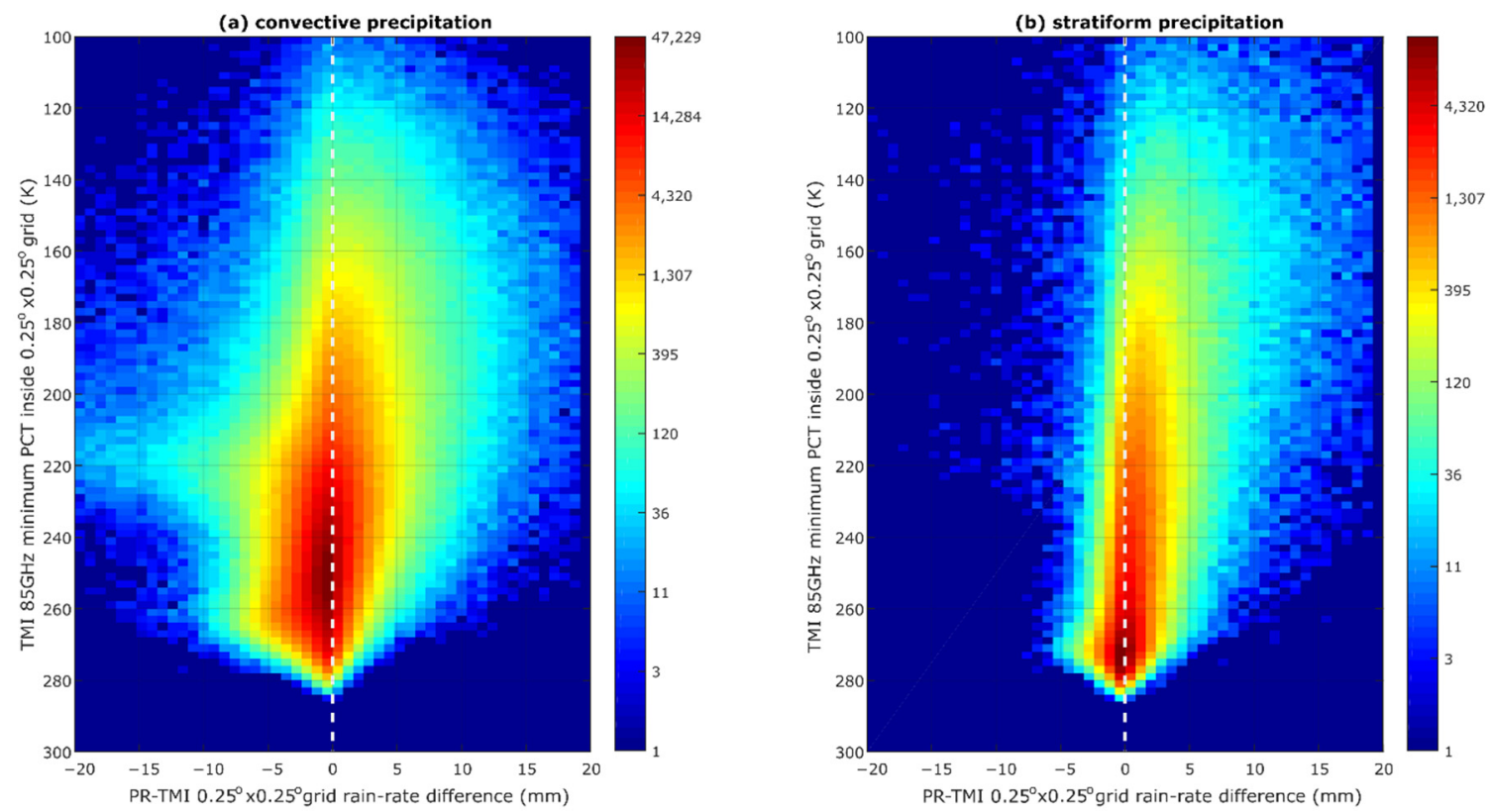

Figure 5. Joint frequency histogram of the gridded rain-rate estimation difference between PR and TMI regarding the minimum TMI $85 \mathrm{GHz}$ PCT value at the same grids for (a) convective precipitation and (b) stratiform precipitation. (Source: data processing).

Figures 6 and 7 show the frequency histogram of the rain-rate difference between the two products at the grid scale regarding $\sigma_{T M I_{-} P C T}$ in the rain-rate database. The results are separated between shallow and deep precipitation systems based on the minimum PCT value. The differences in the shallow precipitation systems are further separated into convective and stratiform systems, which is similar to the previous result. For shallow convective rain, PR estimates a lower rain-rate than TMI when the standard deviation is low (the left of Figure 6). For shallow stratiform rain (the right of Figure 6), PR tends to estimate a higher rain-rate than TMI, particularly when the standard deviations are high.
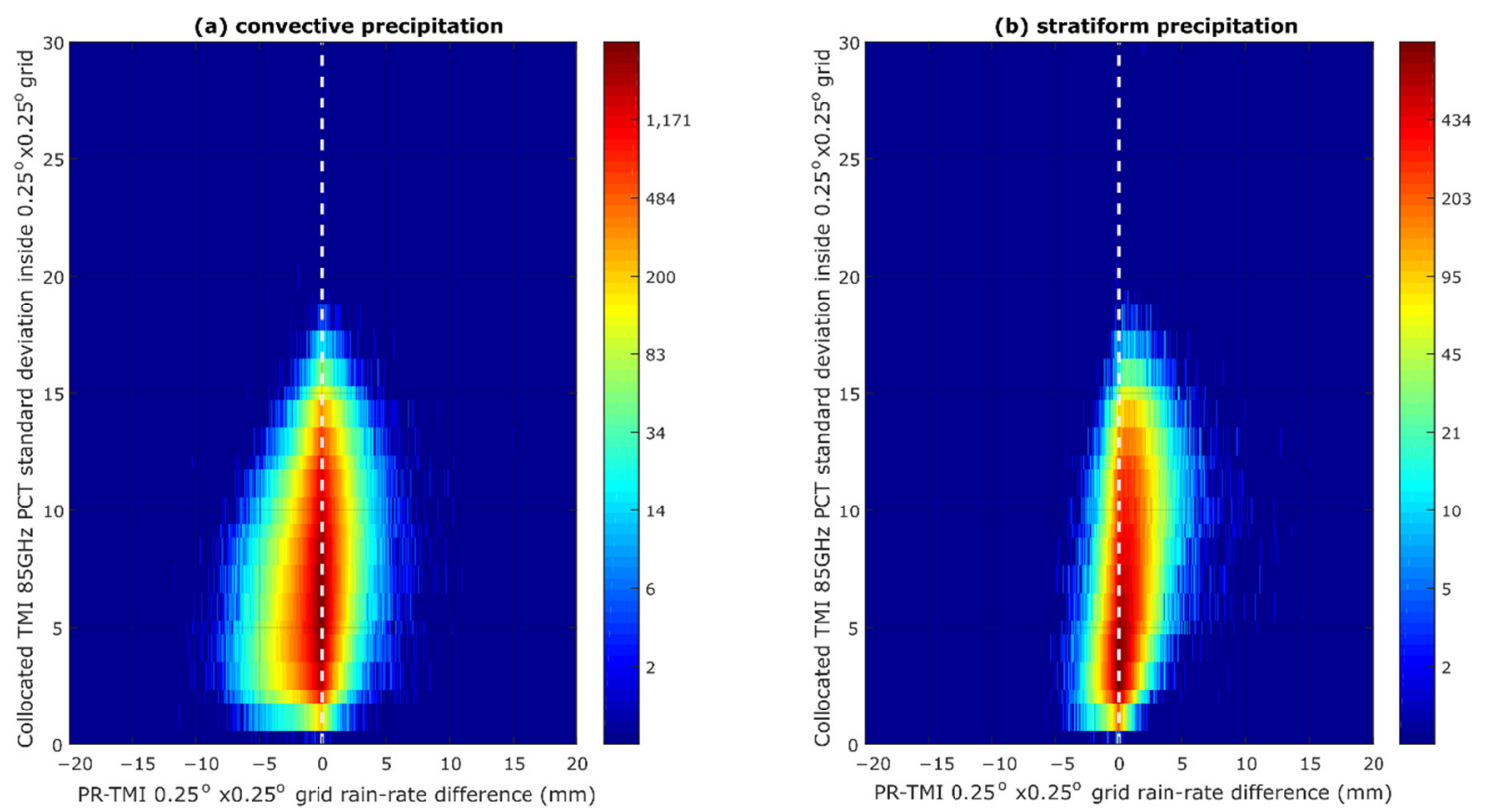

Figure 6. Joint frequency histogram of the gridded rain-rate estimation difference between PR and TMI regarding the standard deviation of TMI $85 \mathrm{GHz}$ PCT at the same grids for (a) shallow convective precipitation and (b) shallow stratiform precipitation. (Source: data processing). 

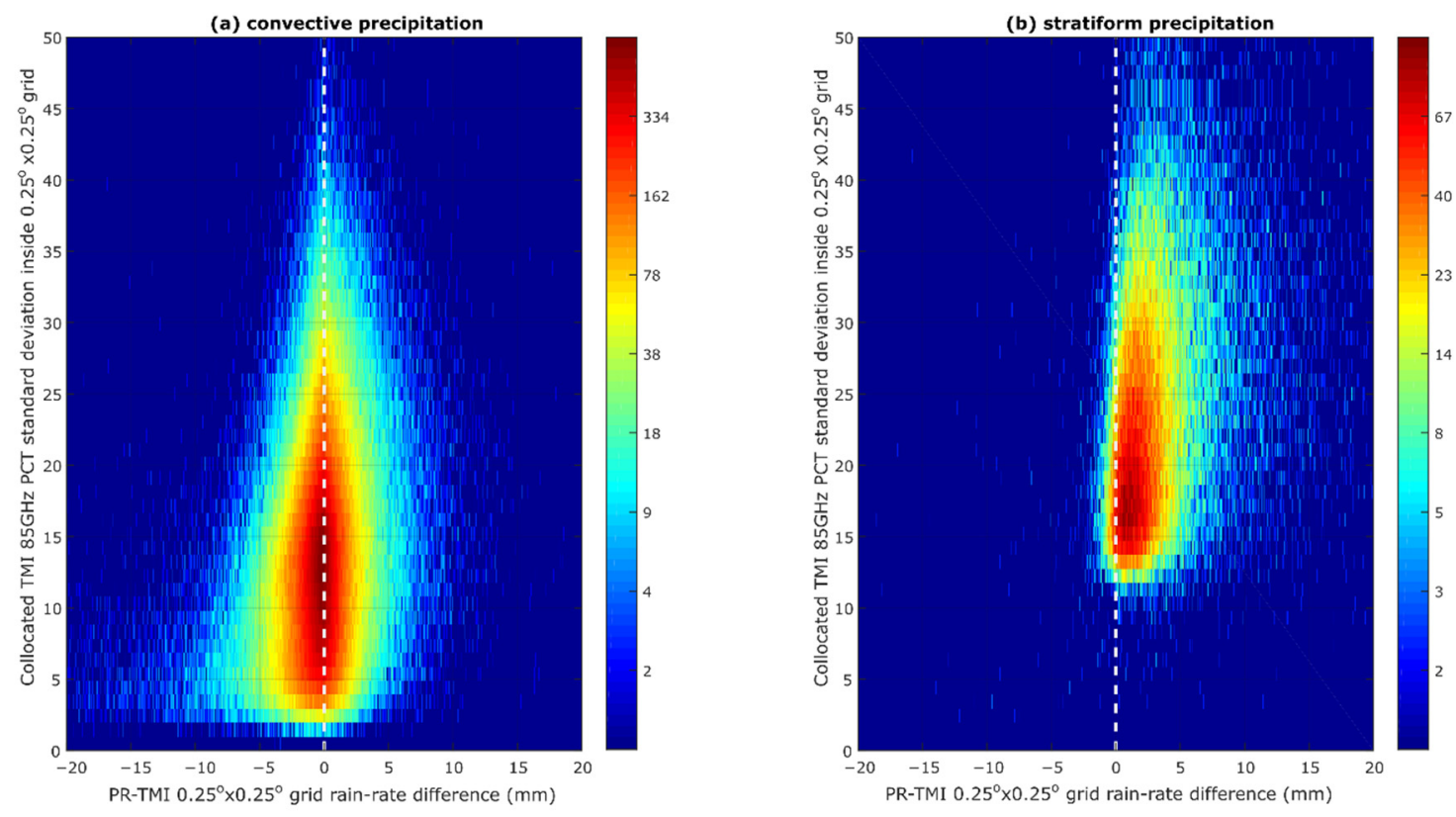

Figure 7. Joint frequency histogram of the gridded rain-rate estimation difference between PR and TMI regarding the standard deviation of TMI 85 GHz PCT at the same grids for (a) deep convective precipitation and (b) deep stratiform precipitation. (Source: data processing).

Figure 7 shows a histogram like the previous figure, but for the deep precipitation system. For deep convective rain, the difference is found particularly when the standard deviation is low. The PR tends to estimate a lower rain-rate than TMI when the precipitation is homogeneous, as indicated by several events at the bottom part of the left figure. However, the distribution of the bias for the higher standard deviation shows a similar frequency between the positive and negative values. For deep stratiform rain, it is clear that PR mostly estimates a higher rain-rate than TMI in all ranges of deviation. The standard deviation of deep stratiform rain is also higher than that of convective rain. The higher standard deviation in the stratiform part might indicate a grid that is inhomogeneous.

\subsection{Implementation of the TMI Rain-Rate Estimation Adjustment}

This subsection shows the result of the adjustment in the grid level based on the approach explained in the methodology. The results are represented in the form of a joint frequency histogram between the rain-rate difference and the grid minimum TMI 85 $\mathrm{GHz}$ PCT value (Min TMI_PCT $_{\text {T }}$ ). The result is also separated into convective and stratiform rain, which is similar to the previous subsection and is referring to the original data and adjustment result. The convective and stratiform fractions from PR are not included in the adjustment since the TMI ice-scattering channel becomes the focus of this analysis.

The comparison before and after adjustment conducted for the El Niño event at the end of 2007 is shown in Figure 8. The original data for convective rain (top left) are slightly biased to the right. This means that TMI tends to estimate a lower rain-rate than PR when there are strong ice-scattering signals. The difference is larger for the stratiform rain original data, where PR tends to estimate higher rain-rates than TMI except for the bottom part (shallow precipitation). The result of the adjustment for convective rain is shown in the bottom left of Figure 8. Although the result shows that the correlation between the two products is higher and the difference in terms of RMSE is lower, the distribution changes slightly to the left. Therefore, at a lower PCT, the adjustment appears to be too high for the original TMI rain-rate. The stratiform rain-rate adjustment is shown in the bottom right of Figure 8. The changes appear to be better than the convective part, as indicated by the improvement in the correlation value and lower RMSE. The histogram also shows improvement in the distribution of the bias to be centered at zero lines. 


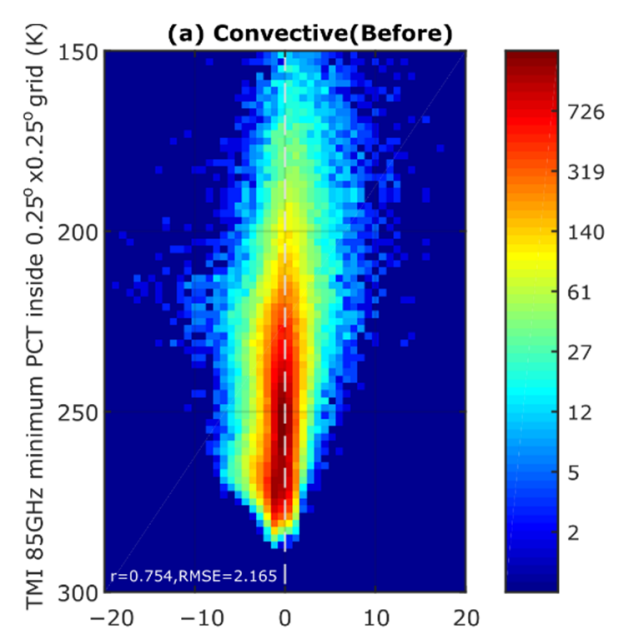

PR-TMI $0.25^{\circ} \times 0.25^{\circ}$ grid rain-rate difference $(\mathrm{mm})$

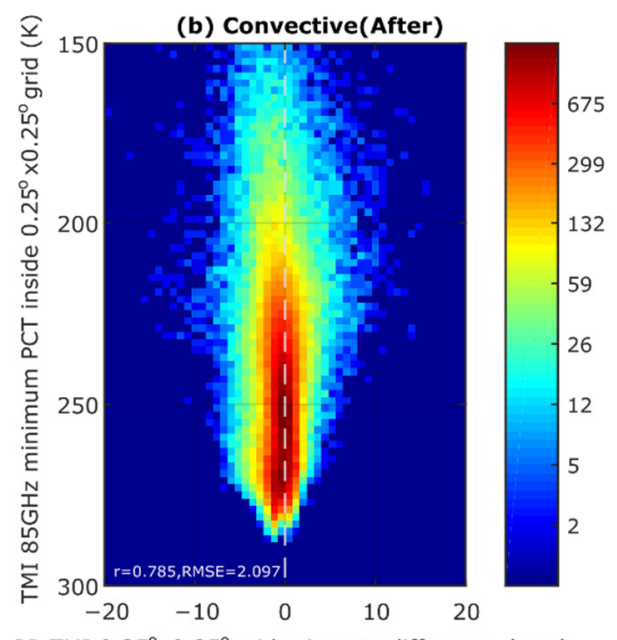

PR-TMI $0.25^{\circ} \times 0.25^{\circ}$ grid rain-rate difference $(\mathrm{mm})$

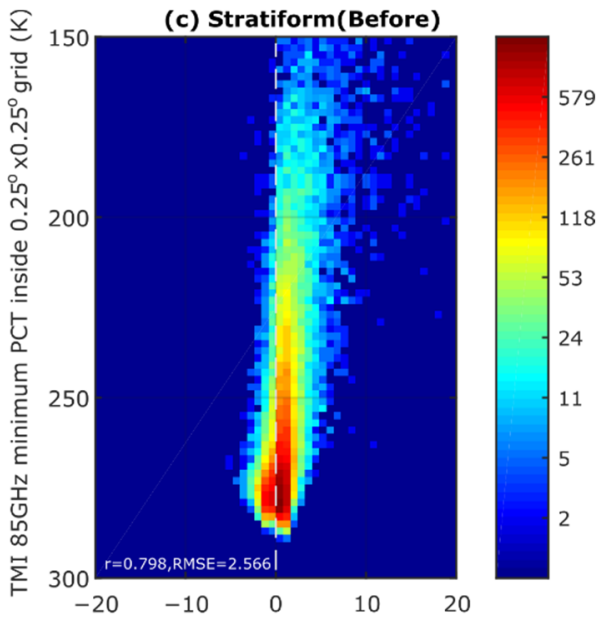

PR-TMI $0.25^{\circ} \times 0.25^{\circ}$ grid rain-rate difference $(\mathrm{mm})$

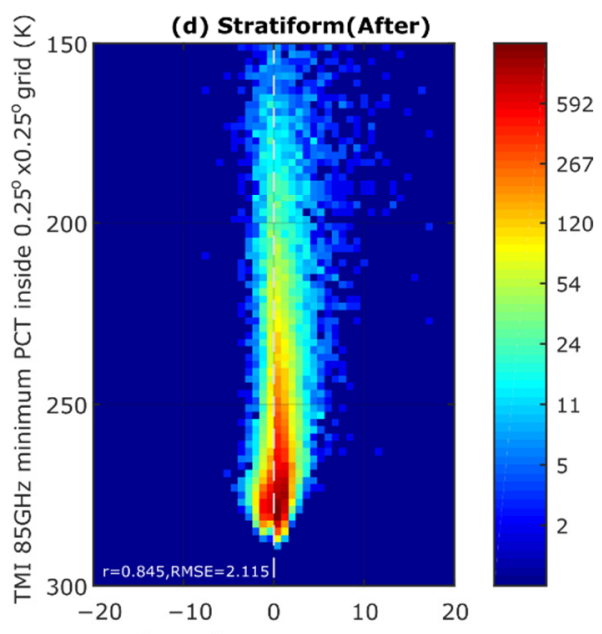

PR-TMI $0.25^{\circ} \times 0.25^{\circ}$ grid rain-rate difference $(\mathrm{mm})$

Figure 8. Comparison of the adjustment result during the El Niño event in 2007. (a) Before the adjustment was implemented for convective precipitation, (b) after the adjustment was implemented for convective precipitation, (c) before the adjustment was implemented for stratiform precipitation, and (d) after the adjustment was implemented for stratiform precipitation (source: data processing).

Figure 9 shows the comparison before and after adjustment, similar to the previous result, but for the La Niña event at the end of 2009. The result is similar to the comparison of El Niño events, where the adjustment is better for stratiform rain than for convective rain. However, it should be noted that there is no clear difference between El Niño and La Niña in terms of distribution regarding the PCT. This means that the relationship between PR and TMI rain estimation bias regarding PCT does not change over time. However, the changes in the frequency of the scale of precipitation organization as affected by ENSO could generate temporal variation, where PR/TMI estimates higher rain-rates. 


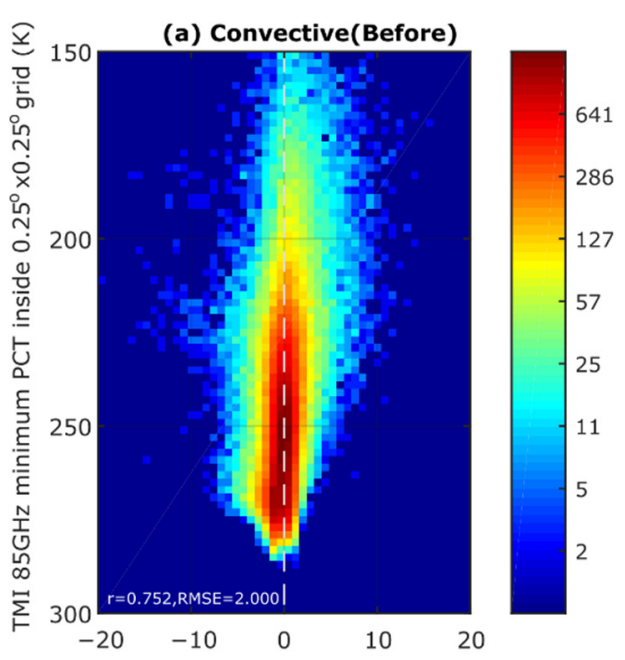

PR-TMI $0.25^{\circ} \times 0.25^{\circ}$ grid rain-rate difference $(\mathrm{mm})$

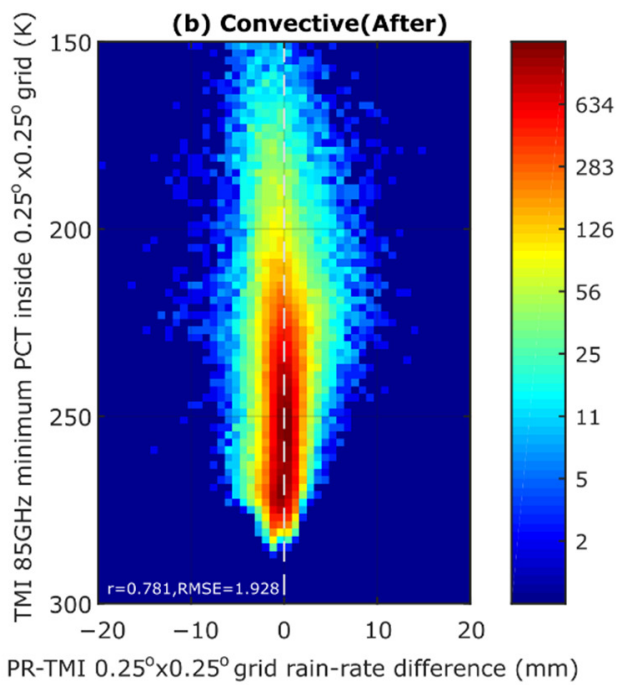

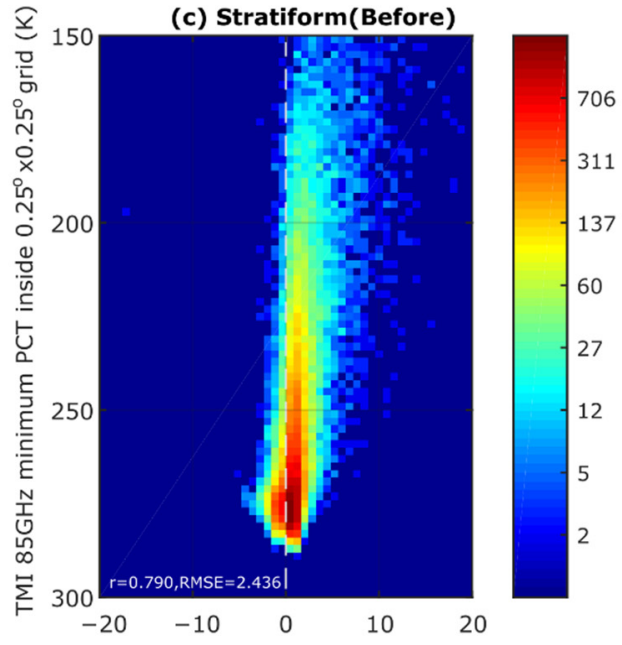

PR-TMI $0.25^{\circ} \times 0.25^{\circ}$ grid rain-rate difference $(\mathrm{mm})$

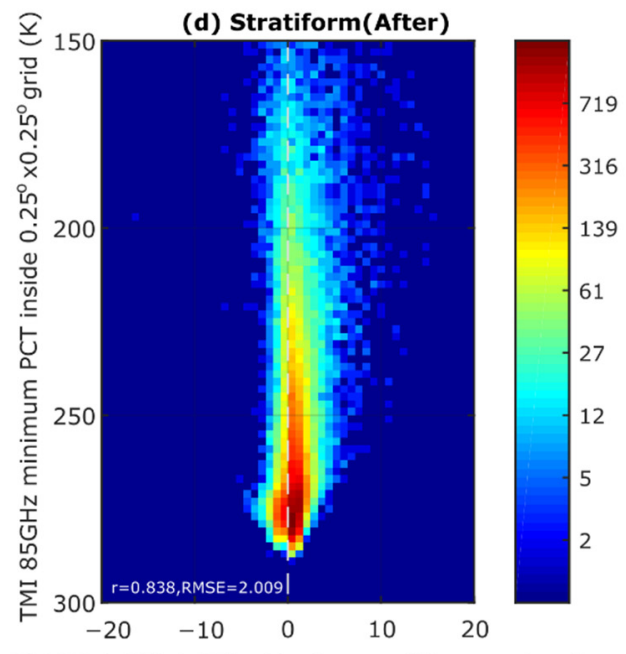

PR-TMI $0.25^{\circ} \times 0.25^{\circ}$ grid rain-rate difference $(\mathrm{mm})$

Figure 9. Comparison of the adjustment result during the La Niña event in 2009. (a) Before the adjustment was implemented for convective precipitation, (b) after the adjustment was implemented for convective precipitation, (c) before the adjustment was implemented for stratiform precipitation, and (d) after the adjustment was implemented for stratiform precipitation (source: data processing).

\section{Discussion}

This section discusses the PR-TMI fundamental difference in rain-rate estimation based on information obtained from the TMI $85 \mathrm{GHz}$ ice-scattering signals, as shown in the previous section. Before the results are discussed, it is important to review the concept behind the ice-scattering signals received by the TMI 85 GHZ channel. Strong ice-scattering signals indicate that there are large amounts of ice particles at the top part of precipitating clouds [32]. This usually happens when strong convective clouds exist at a considerable height above the freezing level [26]. Strong convective clouds are also often associated with heavy rainfall near the surface. Therefore, stronger ice scattering can be interpreted to have a larger amount of ice particles, higher cloud tops, and heavier precipitation.

When there are clouds that contain a specific amount of ice particles with no significant difference from its surroundings over a large area (e.g., at the grid scale, as shown in this research), the precipitation will appear to be homogeneous. In contrast, when there are large differences in the amount of ice particles, there might be a large variation in terms of cloud heights and precipitation. For example, in this study, one of the parameters to 
measure is whether the fraction of TMI $85 \mathrm{GHz}$ PCT is lower than $240 \mathrm{~K}\left(f_{T M I_{-} P C T_{240}}\right)$. The larger number of PCT pixels that are lower than the above threshold, which also have no significant deviation, indicates deep convective clouds that contain a significant amount of rain over a large area. In contrast, a smaller number of PCT pixels lower than the threshold, which is also associated with high deviation, might be interpreted as deep convective clouds surrounded by much lower stratiform clouds.

The TMI is known to underestimate the rain-rate from isolated precipitation systems, which is possibly related to the large TMI footprint for emission channels [21]. In accordance with previous research, the TMI tends to estimate a lower rain-rate than PR for less organized systems, as shown in Figures 3 and 4. The characteristics of TMI estimation in Figure 5 show that it often estimates higher rain-rates than PR for shallow convective precipitation that is heavily organized. In contrast, PR often estimates a higher rain-rate than TMI when there is large variation in the precipitating clouds. Previous research indicates that a higher PR estimation might be associated with less organized precipitation [30]. In addition to the previous research results, this research shows that the higher PR estimation is attributed to precipitating stratiform clouds that contain large variations in ice particles (Figures 6 and 7). The variation in ice particles also means that there are variations in terms of cloud heights and precipitation. The strong ice-scattering signals and their large variation indicate that they might be associated with a small-deep convective system surrounded by stratiform rain, as previously explained. Since the convective part is much less than the stratiform part, in this research, it is classified as stratiform precipitation. It should be noted that TMI estimation also depends on emission channels that have a large footprint. The analysis is conducted at a $0.25^{\circ} \times 0.25^{\circ}$ grid resolution (approximately $27.75 \mathrm{~km} \times 27.75 \mathrm{~km}$ near the equator), while the largest TMI emission footprint is $72 \mathrm{~km} \times 43 \mathrm{~km}$ (at $10 \mathrm{GHz}$ ). This kind of characteristic is not observable from TMI emission channels. As a result, TMI estimates a lower rain-rate than PR.

The TMI rain-rate adjustment explained above indicates that the characteristics related to precipitation homogeneity can influence the rain-rate estimation bias between PR and TMI. Figures 8 and 9 show that the adjustment produces rain-rate estimations from TMI that conform more to PR rain estimation than the original product. However, there are still large variations in the rain-rate estimation bias from the two products, particularly for convective precipitation. The TMI does not have information related to the type of precipitation and therefore is not included in the adjustment. As a result, the method developed in this research does not differentiate convective and stratiform precipitation. Since the estimation bias for stratiform precipitation is relatively linear compared to convective precipitation, the algorithm works well in terms of increasing correlation and lower difference. The adjustment produces a higher rain-rate estimation compared to the original estimation for stratiform precipitation. Therefore, the adjustment could produce rain-rate estimations that conform more closely with PR. However, when a similar adjustment is implemented to convective precipitation, it becomes higher than PR, and the joint histogram is slightly biased to the left.

\section{Conclusions}

In summary, this paper highlights the PR-TMI rain-rate estimation differences that are influenced by precipitation organization and homogeneity. The TMI estimates a higher rain-rate than PR when it detects precipitation from heavily organized precipitation that has homogeneous characteristics. However, it estimates a lower rain-rate than PR when there is deep but less organized precipitation that has inhomogeneous characteristics. The above difference might be associated with TMI emission channels that have a relatively large footprint compared to PR. At the grid level, the information about precipitation organization and homogeneity obtained from the TMI $85 \mathrm{GHz}$ ice-scattering signature could produce adjustments, so TMI rain-rate estimation becomes more consistent with PR to a certain degree. This is particularly applicable for inhomogeneous rain that shows large variations in precipitating clouds and is dominated by stratiform precipitation. The TMI-based ad- 
justment for convective precipitation, although slightly improved, is also influenced by stratiform precipitation that is not differentiated in the rain-rate database.

The differentiation of convective-stratiform precipitation in the adjustment algorithm might produce a better result than that presented in this research. Information about the convective-stratiform fraction might be obtained from PR rain-type products (in PR2A23) and included in the database. However, since the TMI swath is three times larger than the PR swath, the PR rain-type product will only be applicable when the PR and TMI data overlap. In other words, it will not be useful when the only available information is from passive microwave data and therefore is not included in the analysis. Improvement of the footprint size in the future of TRMM satellites, such as GPM, might also reduce the estimation difference. However, the largest footprint for the GPM Microwave Imager is $32 \mathrm{~km} \times 19 \mathrm{~km}$ (at $10.65 \mathrm{GHz}$ ) [33]. Compared to the GPM dual precipitation radar, which has a $5 \mathrm{~km} \times 5 \mathrm{~km}$ footprint, the GPM footprint is still larger. Therefore, bias due to different precipitation organizations and homogeneity is predicted to exist.

This research not only contributes to the improvement of satellite rain-rate estimation products but also gives an insight into how the precipitation process at a small scale (subgrid level) could affect the higher scale (grid level). For example, inhomogeneous rainfall generated by deep isolated precipitation systems could produce a considerable rain-rate at the local scale but is often underestimated at the grid level [13]. In relation to precipitation downscaling, estimating rain-rates at the sub-grid level in the above case often becomes problematic [34]. However, characterization of the ice-scattering signatures as presented in this study also could be considered in the precipitation downscaling process to obtain more reliable results.

Author Contributions: Conceptualization, H.M. and A.B.S.; methodology, A.B.S.; validation, A.B.S. and S.B.W.; formal analysis, A.B.S. and E.N.; investigation, A.B.S.; resources, H.M. and E.N.; writingoriginal draft preparation, A.B.S.; visualization, S.B.W.; supervision, H. M; project administration, E.N. and S.B.W.; funding acquisition, A.B.S. and E.N. All authors have read and agreed to the published version of the manuscript.

Funding: This research was funded by a Grant of "Penelitian Dasar Perguruan Tinggi (PDUPT)— SIMLITABMAS" from the Indonesian Ministry of Education and Culture in 2021 with Dr. Andung Bayu Sekaranom as the principal investigator (Contract number: 1632/UN1/DITLIT/DIT-LIT/2021).

Institutional Review Board Statement: Not applicable.

Informed Consent Statement: Not applicable.

Data Availability Statement: TRMM PR (2A25) and TMI (2A12), and other TRMM datasets (TMI1B11, PR2A23) analyzed in this work are available online from the NASA Precipitation Measurement Mission (PMM) archives (https:/ / pmm.nasa.gov/data-access/downloads/TRMM) accessed in 30 September 2018.

Conflicts of Interest: The authors declare no conflict of interest.

\section{References}

1. Kummerow, C.; Simpson, J.; Thiele, O.; Barnes, W.; Chang, A.T.C.; Stocker, E.; Adler, R.F.; Hou, A.; Kakar, R.; Wentz, F.; et al. The Status of the Tropical Rainfall Measuring Mission (TRMM) after Two Years in Orbit. J. Appl. Meteorol. 2000, 39, $1965-1982$. [CrossRef]

2. Ichikawa, H.; Yasunari, T. Time-space characteristics of diurnal rainfall over Borneo and surrounding oceans as observed by TRMM-PR. J. Clim. 2006, 19, 1238-1260. [CrossRef]

3. Yamamoto, M.K.; Furuzawa, F.A.; Higuchi, A.; Nakamura, K. Comparison of diurnal variations in precipitation systems observed by TRMM PR, TMI, and VIRS. J. Clim. 2008, 21, 4011-4028. [CrossRef]

4. Prat, O.P.; Nelson, B.R. Characteristics of annual, seasonal, and diurnal precipitation in the Southeastern United States derived from long-term remotely sensed data. Atmos. Res. 2014, 144, 4-20. [CrossRef]

5. Qian, J.-H. Why Precipitation Is Mostly Concentrated over Islands in the Maritime Continent. J. Atmos. Sci. 2008, 65, 1428-1441. [CrossRef]

6. Song, H.-J.; Sohn, B.-J.; Hong, S.-Y.; Hashino, T. Idealized numerical experiments on the microphysical evolution of warm-type heavy rainfall. J. Geophys. Res. Atmos. 2017, 122, 1685-1699. [CrossRef] 
7. Kummerow, C.; Hong, Y.; Olson, W.S.; Yang, S.; Adler, R.F.; Mccollum, J.; Ferraro, R.; Petty, G.; Shin, D.-B.; Wilheit, T.T. The Evolution of the Goddard Profiling Algorithm (GPROF) for Rainfall Estimation from Passive Microwave Sensors. J. Appl. Meteorol. Climatol. 2001, 40,1801-1820. [CrossRef]

8. Huffman, G.J.; Bolvin, D.T.; Nelkin, E.J.; Wolff, D.B.; Adler, R.F.; Gu, G.; Hong, Y.; Bowman, K.P.; Stocker, E.F. The TRMM Multisatellite Precipitation Analysis (TMPA): Quasi-Global, Multiyear, Combined-Sensor Precipitation Estimates at Fine Scales. J. Hydrometeorol. 2007, 8, 38-55. [CrossRef]

9. Turk, F.J; Xian, P. An assessment of satellite-based high resolution precipitation datasets for atmospheric composition studies in the maritime continent. Atmos. Res. 2013, 122, 579-598. [CrossRef]

10. Liu, C.; Zipser, E. Differences between the Surface Precipitation Estimates from the TRMM Precipitation Radar and Passive Microwave Radiometer Version 7 Products. J. Hydrometeorol. 2014, 15, 2157-2175. [CrossRef]

11. Iguchi, T.; Kozu, T.; Meneghini, R.; Awaka, J.; Okamoto, K. Rain-profiling algorithm for the TRMM precipitation radar. J. Appl. Meteorol. 2000, 39, 2038-2052. [CrossRef]

12. Schumacher, C.; Houze, R.A. Comparison of radar data from the TRMM satellite and Kwajalein oceanic validation site. J. Appl. Meteorol. 2000, 39, 2151-2164. [CrossRef]

13. Sekaranom, A.B.; Masunaga, H. Comparison of TRMM-Derived Rainfall Products for General and Extreme Rains over the Maritime Continent. J. Appl. Meteorol. Climatol. 2017, 56, 1867-1881. [CrossRef]

14. Iguchi, T.; Kozu, T.; Kwiatkowski, J.; Meneghini, R.; Awaka, J.; Okamoto, K. Uncertainties in the rain profiling algorithm for the TRMM precipitation radar. J. Meteorol. Soc. Japan. Ser. II 2009, 87, 1-30. [CrossRef]

15. Kozu, T.; Iguchi, T.; Kubota, T.; Yoshida, N.; Seto, S.; Kwiatkowski, J.; Takayabu, Y.N. Feasibility of raindrop size distribution parameter estimation with TRMM precipitation radar. J. Meteorol. Soc. Japan. Ser. 2009, 87, 53-66. [CrossRef]

16. Fu, Y.; Liu, G. The Variability of Tropical Precipitation Profiles and Its Impact on Microwave Brightness Temperatures as Inferred from TRMM Data. J. Appl. Meteorol. 2001, 40, 2130-2143. [CrossRef]

17. Kummerow, C. Beamfilling Errors in Passive Microwave Rainfall Retrievals. J. Appl. Meteorol. 1998, 37, 356-370. [CrossRef]

18. Berg, W.; L'Ecuyer, T.; Kummerow, C. Rainfall climate regimes: The relationship of regional TRMM rainfall biases to the environment. J. Appl. Meteorol. Climatol. 2006, 45, 434-454. [CrossRef]

19. Carr, N.; Kirstetter, P.; Hong, Y.; Gourley, J.J.; Schwaller, M.; Petersen, W.; Wang, N.; Ferraro, R.R.; Xue, X. The influence of surface and precipitation characteristics on TRMM TMI rainfall retrieval uncertainty. J. Hydrometeorol. 2015, 16, 1596-1614. [CrossRef]

20. Gopalan, K.; Wang, N.-Y.; Ferraro, R.; Liu, C. Status of the TRMM 2 A12 land precipitation algorithm. J. Atmos. Ocean. Technol. 2010, 27, 1343-1354. [CrossRef]

21. Sekaranom, A.B.; Masunaga, H. Origins of heavy precipitation biases in the TRMM PR and TMI products assessed with cloudsat and reanalysis data. J. Appl. Meteorol. Climatol. 2019, 58, 37-54. [CrossRef]

22. Masunaga, H.; Iguchi, T.; Oki, R.; Kachi, M. Comparison of rainfall products derived from TRMM microwave imager and precipitation radar. J. Appl. Meteor. 2002, 41, 849-862. [CrossRef]

23. Kummerow, C.; Poyner, P.; Berg, W.; Thomas-Stahle, J. The effects of rainfall inhomogeneity on climate variability of rainfall estimated from passive microwave sensors. J. Atmos. Ocean. Technol. 2004, 21, 624-638. [CrossRef]

24. Zagrodnik, J.P.; Jiang, H. Investigation of PR and TMI version 6 and version 7 rainfall algorithms in landfalling tropical cyclones relative to the NEXRAD stage-IV multisensor precipitation estimate dataset. J. Appl. Meteorol. Climatol. 2013, 52, $2809-2827$. [CrossRef]

25. Rajendran, K.; Nakazawa, T. Systematic differences between TRMM 3G68 PR and TMI rainfall estimates and the possible association with life cycle of convection. Sola 2005, 1, 165-168. [CrossRef]

26. Hamada, A.; Takayabu, Y.N.; Liu, C.; Zipser, E.J. Weak linkage between the heaviest rainfall and tallest storms. Nat. Commun. 2015, 6, 1-6. [CrossRef]

27. Simpson, J.; Kummerow, C.; Tao, W.-K.; Adler, R.F. On the Tropical Rainfall Measuring Mission (TRMM). Theor. Appl. Clim. 1996, 60, 19-36. [CrossRef]

28. Schumacher, C.; Houze, R.A. The TRMM precipitation radar's view of shallow, isolated rain. J. Appl. Meteorol. 2003, 42, 1519-1524. [CrossRef]

29. Spencer, R.W.; Goodman, H.M.; Hood, R.E. Precipitation retrieval over land and ocean with the SSM/I: Identification and characteristics of the scattering signal. J. Atmos. Ocean. Technol. 1989, 6, 254-273. [CrossRef]

30. Henderson, D.S.; Kummerow, C.D.; Berg, W. ENSO Influence on TRMM Tropical Oceanic Precipitation Characteristics and Rain Rates. J. Clim. 2018, 31, 3979-3998. [CrossRef]

31. Henderson, D.S.; Kummerow, C.D.; Marks, D.A.; Berg, W.A. Regime-Based Evaluation of TRMM Oceanic Precipitation Biases. J. Atmos. Ocean. Technol. 2017, 34, 2613-2635. [CrossRef]

32. Kelley, O.A.; Stout, J.; Summers, M.; Zipser, E.J. Do the tallest convective cells over the tropical ocean have slow updrafts? Mon Weather Rev. 2010, 138, 1651-1672. [CrossRef]

33. Liu, Z.; Ostrenga, D.; Vollmer, B.; Deshong, B.; Macritchie, K.; Greene, M.; Kempler, S. Global precipitation measurement mission products and services at the NASA GES DISC. Bull. Am. Meteorol. Soc. 2017, 98, 437-444. [CrossRef]

34. De Luca, D.L. Analysis and modeling of rainfall fields at different resolutions in Southern Italy. Hydrol. Sci. J. 2014, 59, 1536-1558. [CrossRef] 